\title{
Viability of Use of PVC Tubes in Solar Collectors: An Analysis of Materials
}

\author{
Luiz Guillherme Meira de Souza, Uílame Umbelino Gomes \\ Departamentos de Física Teórica e Experimental e Engenharia Mecânica da Universidade \\ Federal do Rio Grande do Norte, Campus Universitário, Lagoa Nova, Natal - RN, Brazil
}

Received: September 16, 2002; Revised: March 03, 2003

\begin{abstract}
This paper presents a study of the inherent degradations of PVC tubes due to the thermal effect and ultraviolet solar radiation. The approach relates its causes and its effect of use of the PVC tubes as elements to absorption, forming a coil, in solar collectors for water heating. It is demonstrated that such degradations can be burst through the use of an outflow and an appropriate regimen of work, as well as of a protective layer for the tubes, in this case black ink used to magnify its absorption. The results of the properties of tubes that had been exposed to the degradation effect for up to five years are presented. The viability of use of this type of collector is demonstrated through comparative analysis of tubes exposed and not exposed to the sun, concluding for the low cost, easy assembly and maintenance of the system.
\end{abstract}

Keywords: thermal degradation, UV degradation, element to absorption of PVC

\section{Introduction}

In a solar collector with PVC tubes, the first question that arises is about its degradation. Specialized literature shows that the susceptibility to the thermal degradation of PVC reaches a critical level from temperature above $60^{\circ} \mathrm{C}$ in its surface. The UV degradation also represents a restriction to the use of solar collectors made of PVC tubes, once radiations with this wavelength affect the mechanical integrity of this kind of material ${ }^{1-6}$.

As the PVC tube is well less expensive than copper, we developed, constructed and studied, in the Laboratory of Solar Energy/UFRN, two types of alternative solar collectors with absorption coils of PVC tubes, the wing and labyrinth collectors, shown in Fig. 1. The study demonstrated the thermal viability of those collectors, which work in regimen of continuous flow, with only one pass of the fluid for the inward of the same ones ${ }^{7-11}$.

The changes of the mechanical properties of the PVC tubes, exposed to the sun for periods of one year, three years and five years with and without painting were studied. In these studies, the baseline was a PVC tube that was neither exposed to the sun, nor crossed by a hot fluid. We determined the properties of traction, compression, bend and impact. The analyses was compared to those performed in the tube that was never exposed to the heat and solar radiation, and will be expressed through a parameter $(\delta)$ that relates the property of the sample with of the standard tube.

\section{Literature Review}

Although the degradation of polyvinyl chloride has been well studied, there is much controversy, which needs to be cleared. Some mechanisms of the degradation (radicalic, ionic, and molecular) were proposed with base on various experimental works. Several studies present different degradation mechanisms related to different kinetic parameters, which demonstrate the susceptibility the degradation of PVC when exposed to the heat and the ultraviolet radiation.

Jordan ${ }^{12}$ determined kinetic parameters of the dehydrochlorination of poly (vynil chloride), using thermogravimetric analysis, that were: order of apparent reaction, energy of apparent activation and factor of apparent frequency, following the model of Carrol and Freeman. Four different degradation mechanisms were deduced: final dehydrochlorination, random chain scission, ciclization and coke. These four mechanisms are mentioned in agreement with the order of appearance.

Petre $^{13}$ presented some mechanisms mentioned by the literature to explain the degradations of poly (vynil chlo-

*e-mail: lguilherme@dem.ufrn.br, umbelino@dfte.ufrn.br 


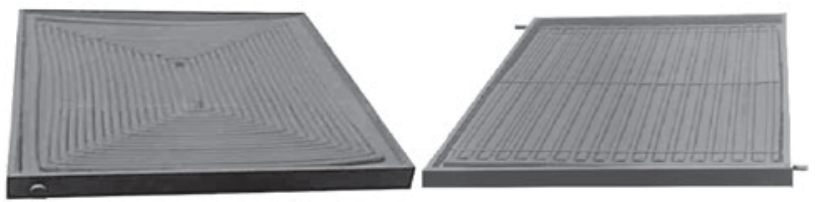

Figure 1. The wing and labyrinth collectors.

ride) when exposed to the heat and the ultraviolet radiation. It showed that a first degradation process which occurs at lower temperature, consist mainly of dehydrochlorination either with initiation at the defects in the polymeric chain (double bonds, tertiary and allylic chlorine, branching, etc) or by random initiation in any point of the chain.

Fisch $^{14}$ has shown that the polyvinyl chloride thermal degradation is the result of a "zipper dehydrochlorination" process that involves allylic chlorides as intermediates and is catalyzed by hydrochloric acid.

Bacaloglu ${ }^{15}$ has demonstrated that the degradation of polyvinyl chloride is a complex chain dehydrochlorination that consists of an initiation process to generate an active intermediate and a series of chain reactions that generates additional active intermediates with progressively increased numbers of double bonds.

Yarahmadi ${ }^{16}$ also demonstrated that this type of degradation is critical during the process of manufacture of PVC, when the same is melted and soon after extruded. The degraded polymer loses its plasticity, passing to a rigid composition. Despite the sensitivity that the PVC presents in relation to the heat, it is easily processed with the composite that will give its ideal composition.

Additives as stabilizers, lubricants, loads and pigments are used to inhibit the degradation of poly (vynil chloride), facilitating its processing. The stabilizers are very important compounds, because they enhance the thermal stability of polymer, giving it conditions to support the heating that the process requires. These products react with hydrochloric acid $^{17-18}$.

The thermal results obtained with the collectors in study, they demonstrate the viability of use of those collectors that use tubes of PVC as elements to absorption of solar radiation. However so that this collector type can be competitive in market terms, in relation to the available collectors, it is necessary a study about the relative degradations to the use of PVC, that is related to the time of useful life of the proposed prototype. It becomes imperious to quantify the levels of thermal and UV degradations as related by Torikai ${ }^{19}$.

An important aspect of the use of the PVC tube as absorption element in a solar collector is the painting of black color ink, for the absorption of the radiation solar and consequent transformation in heat. This film creates a protective layer in the tube, protecting it against the ultraviolet radiation, decreasing the waste for UV. However, this same film provokes a temperature increase in the tube, making it more susceptible to thermal degradation. For the painting of the tubes was used an ink manufactured in LES/UFRN, alternative to the conventional inks, enamel synthetic and automotiva, available commercially.

We focused in the study of available tubes in the market, trying to create conditions to making it thermal absorber, without reaching degradation level.

Sullivan $^{20}$, and Ragab ${ }^{5}$, demonstrated that the thermal and for UV degradations induce fragility to the material, but the quantification of these levels of degradation is not available. Jordan ${ }^{12}$, proved that this embrittlement could be translated by the loss of mass or through the loss of hydrogen chloride and the consequent sprouting of double bonds.

This work it tries to demonstrate the changes in the properties caused by to display of the samples to temperature levels and global solar radiation, for several periods of time.

\section{Experimental Procedure}

The thermogravimetric (TG) measurements were taken in order to determine the loss of mass, when the tubes were exposed to solar radiation, sampling 1,301 mg of PVC, with five years of exposure to the sun, submitting the sample to a temperature range of $0-600{ }^{\circ} \mathrm{C}$, at a rate of $5.0{ }^{\circ} \mathrm{C} / \mathrm{min}$ of heating.

In order to evaluate the behavior of the PVC tubes exposed to long periods of solar radiation, and which the property alterations in relation to the tube never exposed, some compared properties had been determined and soon after calculated parameters $(\delta)$ that relates the property of the sample in the study to the properties of the standard sample. Tests of traction, compression, bend and impact, in the five samples of the each type studied, were carried out, to analyze the waste levels associated to the thermal and UV degradations and evaluate its causes and effects ${ }^{1-5,22-32}$. The comparative parameters $(\delta)$ they are calculated in agreement with the Eq. 1 .

$$
\delta=\frac{\text { Property of the sample in the study }}{\text { Property of the standard sample }}
$$

To analyze the microstructure of degradation of the tubes submitted to the action of the solar rays a scan electron microscope was used. The samples were analyzed in its internal and external surfaces.

Five samples of standard tubes (NS) were submitted to one year (1YBP), three years (3YBP, 3YWP) and five years (5YBP, 5YWP) of sun exposure, with and without black color film.

To evaluate the absorption power of the used alternative ink, a mixture of white washable ink with powdered coloring 
black, it took place comparative tests with painted tubes with black opaque synthetic enamel and alternative opaque black. The external temperature of the tubes was measured it, maintained under constant level of global solar radiation, inside a covered box for transparent plane glass. It also took place an spectrophotometry of the used black ink, for the region of the ultraviolet and visible, to evaluate the absorption power of the black film that it recovers the PVC tube, diagnosing your effect softening of the degradation for exhibition to the ultraviolet solar radiation.

As the objective principal of the work was to avoid that the tubes to absorption reached the critical temperature to the beginning of the process of degradation, it was measured the values of the external temperature of the same ones in several points of the serpentine, to evaluate the behavior of that parameter. The system was tested with several outflow levels, to diagnose the reach or not of the degradation temperature, being determined for which levels are possible to avoid that the tubes of PVC reaches the critical temperature of degradation.

\section{Results and Discussion}

\subsection{Thermogravimetric Analysis}

Figure 2 shows a curve of TG for the sample of PVC tube with five year of exposure to the sun, with black film, without circulating fluid and the standard curve for a sample of PVC never exposed.

The thermogravimetrics curves for the samples NS and $5 Y B P$, they have a similar plenty profile, demonstrating that the more significant loss of that takes place for the range of corresponding temperature $223{ }^{\circ} \mathrm{C}-370{ }^{\circ} \mathrm{C}$, with one loss of about $55 \%$. For the temperature of $600{ }^{\circ} \mathrm{C}$ the mass trash that remains corresponds to $3,9 \%$ approximately. In the range of inherent temperature the use of the PVC as element to absorb radiation in a solar collector, the level of loss of mass is insignificant, with one loss of about $10 \%$ for both samples.

\subsection{Mechanical Properties Measurements}

The data of the relative comparative parameters $(\delta)$ raised for the tensile, compression, bend and impact tests are shown in the Table 1 and Table 2. Table 1 shows the parameters of the traction and Table 2 the values of traction, compression, bend and impact resistance.

Table 1 shows an increase in the rigidity of the tubes exposed for more time to the solar radiation and covered with the film of opaque black, that it can be diagnosed by the increase in the resistance to the traction, in the modulus of elasticity and a significant decrease of the plastic deformation. In relation the loss of elastic deformation, the values of the comparative factors demonstrate a small loss for the exposed tubes in the sun and painted. For the sample

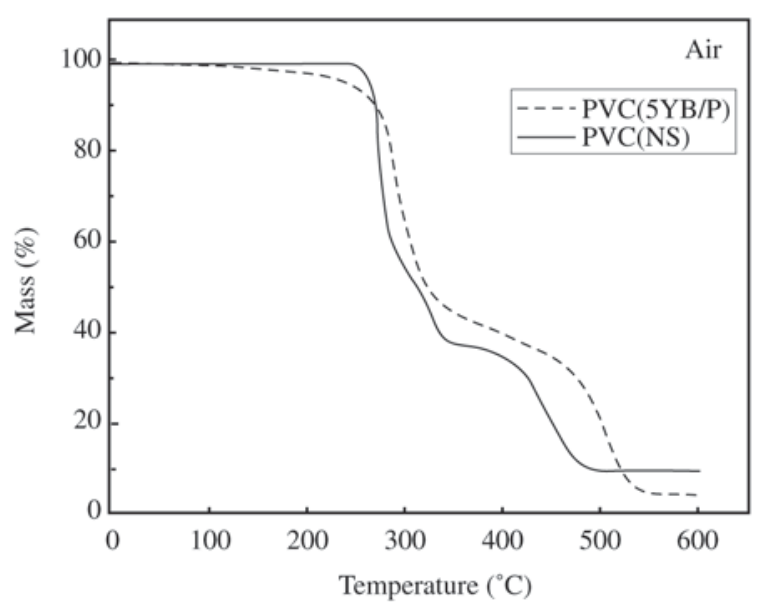

Figure 2. Data of the thermogravimetric analysis.

Table 1.Values of parameters $(\delta)$ of traction tests, where $\delta_{\mathrm{TS}}, \delta_{\mathrm{E}}$ $\delta_{\mathrm{YS}}, \delta_{\mathrm{PD}}$ and $\delta_{\mathrm{ED}}$ are the comparative mean parameters of tensile strength, of modulus of elasticity, of yield strength, of plastic deformation and of the elastic deformation.

\begin{tabular}{lccccc}
\hline TYPE & $\delta_{\mathrm{TS}}$ & $\delta_{\mathrm{E}}$ & $\delta_{\mathrm{YS}}$ & $\delta_{\mathrm{PD}}$ & $\delta_{\mathrm{ED}}$ \\
\hline NS & 1.00 & 1.00 & 1.00 & 1.00 & 1.00 \\
3YWP & 0.95 & 1.04 & 0.81 & 0.27 & 0.75 \\
5YWP & 0.95 & 1.1 & 0.86 & 0.24 & 0.78 \\
1YBP & 1.08 & 1.15 & 0.99 & 0.13 & 0.82 \\
3YBP & 1.11 & 1.15 & 1.00 & 0.10 & 0.98 \\
5YBP & 1.15 & 1.15 & 1.07 & 0.09 & 0.98 \\
\hline
\end{tabular}

Table 2. Mean comparative parameters $(\delta)$ of the raised mechanical properties, where $\delta_{\mathrm{TS}}, \delta_{\mathrm{CS}}, \delta_{\mathrm{BS}}$ and $\delta_{\mathrm{IE}}$ are the average comparative parameters of the traction, compression, bend and impact.

\begin{tabular}{lcccc}
\hline TYPE & $\delta_{\text {TS }}$ & $\delta_{\mathrm{CS}}$ & $\delta_{\mathrm{BS}}$ & $\delta_{\text {IE }}$ \\
\hline NS & 1.00 & 1.00 & 1.00 & 1.00 \\
3YWP & 0.95 & 0.99 & 0.98 & 0.52 \\
5YWP & 0.95 & 0.96 & 0.98 & 0.52 \\
1YBP & 1.08 & 1.10 & 1.08 & 0.42 \\
3YBP & 1.11 & 1.09 & 1.06 & 0.42 \\
5YBP & 1.15 & 1.16 & 1.08 & 0.32 \\
\hline
\end{tabular}

$5 \mathrm{YBP}$, the data point an increment of $15 \%$ in the resistance to the traction and in the module of elasticity; a small elevation in the yield tension; a significant reduction in relation to the plastic deformation, above $90 \%$ and a small decrease in the elastic deformation. 
One perceives clearly that the property more affected by the exposure of the PVC tubes to radiation, with consequent increase of temperature in function of black color, is the impact, in accordance to Sullivan ${ }^{22}$ and Ragab ${ }^{5}$, with a reduction in its energy for rollback of $68 \%$ for the sample spotted of black color exposed to the sun for five years. In spite of that significant loss in the resistance to the impact, the tubes of PVC used as elements to absorption in solar collectors they are not subject to this load type, what doesn't bring any restriction type to the use of tubes of this material in the function of conductors of heat. The tensile resistance had an increase of $15 \%, 16 \%$ in the compression resistance, $8 \%$ in the bend resistance, of the tube that was exposed to the sun and painted of black color, passed exposed more time, compared to the standard.

\subsection{Micrographs Analysis}

Figures 3 and 4 show the micrographs carried through with a scan electron microscope, in vacuous low, for the samples that had been exposed more time, 5YWP and 5YBP and the standard samples, NS. The scan electron microscope used was XL30 of Phillips, with capacity of increase of $100.000 \times$, capacity of vacuum of $3,7 \times 10^{-6} \mathrm{mbar}$ to 20 torr, for high and vacuous low, respectively. The magnitude of used amplification was of $650 \times$ and the work range, in vacu- ous low, it was of 0,4 torr.

The analysis of the micrographs shows that the type of degradation for the samples that had been exposed without painting is different to those presented by the samples that had been covered with black ink. The micrographs confirms the inherent degradations of PVC tubes exposed to the action of the solar rays, and shows differences between UV degradation, higher level in the tubes not spotted, and predominant thermal degradation in the painted tubes, being those differences associated to the effect of reduction of the degradation for inhibition to the ultraviolet radiation obtained with the opaque black ink film

The samples painted of black, and exposed in the sun, they presented a progressive degradation in function of the time of exhibition, that is characterized by appearance of bubbles of $\mathrm{HCl}$, that gradually are going growing progressively, causing eclosion, with consequent material loss.

The types of degradation reveal different forms: for UV, through cracks and thermal for multipunctual defects ones, provoked by the mass loss, both in the microstructure. By rough estimate naked was not evidenced the occurrence of fractions, cracks, punctures or other types of defects, that compromised the use of the PVC tubes as elements for the absorption of radiation.
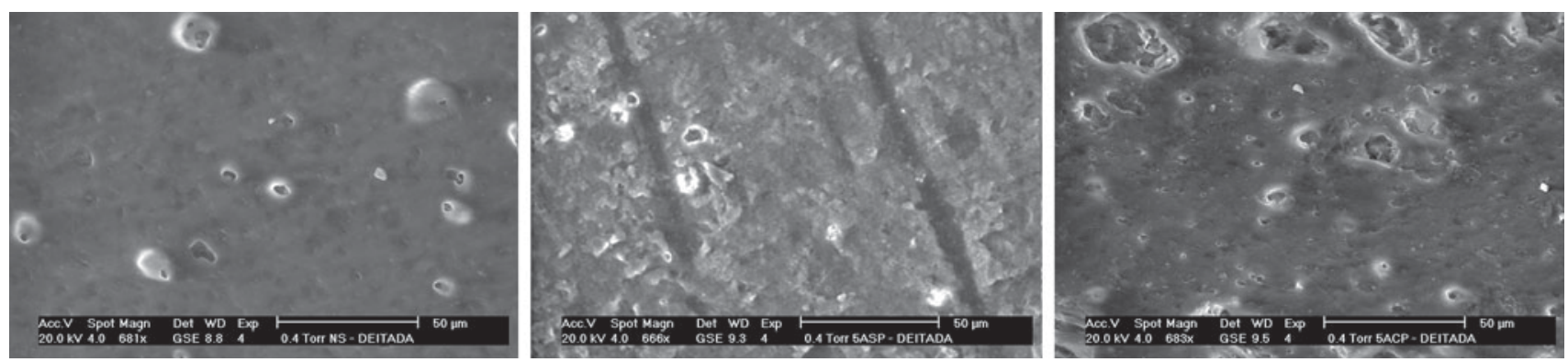

Figure 3. SEM micrograph of the internal surfaces of the samples for (a) NS; (b) 5YWP; (c) 5YBP.
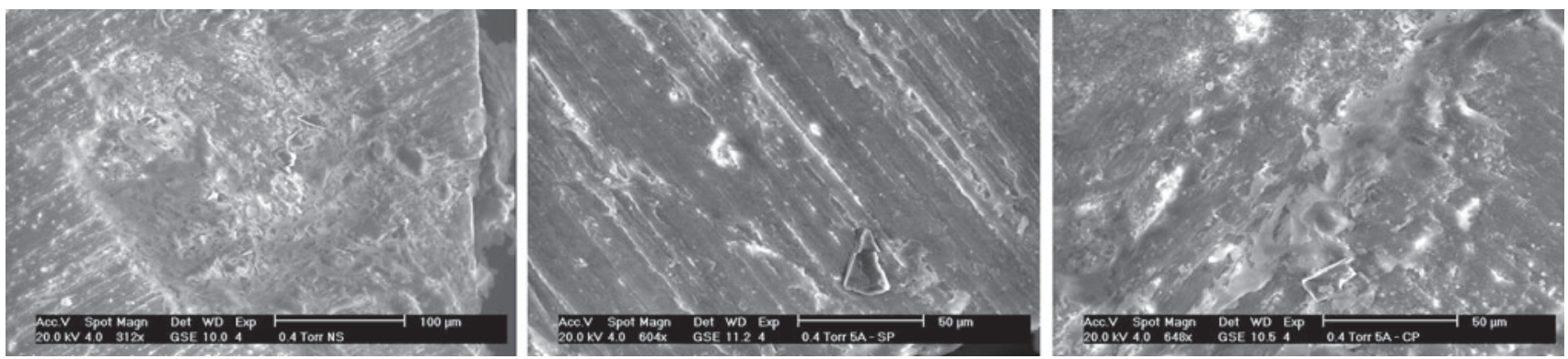

Figure 4. SEM micrograph of the external surfaces of the samples for (a) NS; (b) 5YWP; (c) 5YBP. 


\subsection{Analysis of the Absorption Power of the Produced Alternative Ink}

Figure 5 display the behavior of the external temperature of the tubes to absorption in a solar collector, painted with opaque black ink conventional and with the alternative ink.

The measured data show that the absorption power of the opaque black ink produced it is practically identical to of the ink it enamels synthetic conventional, once them temperature of the external surface of the tubes they were practically identical. For the obtaining of 3,6 1 of alternative ink it was used 2,0 1 of white washable ink for interiors and exteriors mixed with $500 \mathrm{mg}$ of black pigment and 1,0 1 of water. The produced ink had cost of $\mathrm{R} \$ 14,80 / \mathrm{gal}$ of 3,6 l, what represents an economy of $66 \%$ in relation to the conventional ink of equivalent cost $R \$ 43,81$ for the same volume.

Figure 6 display the results of a spectrophotometry accomplished with the pigment to diagnose the absorption power of the ink in relation to the ultraviolet radiation.

The spectrophotometry accomplished for the ranges of the visible and of the ultraviolet it demonstrates the absorption power of the pigment used for these regions, mainly for the ultraviolet, when it reaches absortivity values of up to $85 \%$, protecting the exposed tube of the harmful effects of this radiation. Therefore, the ink film used in the tubes, to endow them of a larger absorption power, inherent the obtaining of the thermal energy starting from the solar radiation, protects the tubes, representing an element to soften the degradation of PVC for ultraviolet radiation. The used pigment is a composition the base of Oxide of black Iron (30 to 60\%) and in your composition it contains Carbonate of Calcium and Magnesium (15 to 40\%), Fume Black (10 to 30\%) and Ácid Naftalen Sulfonic (1 to 5\%).

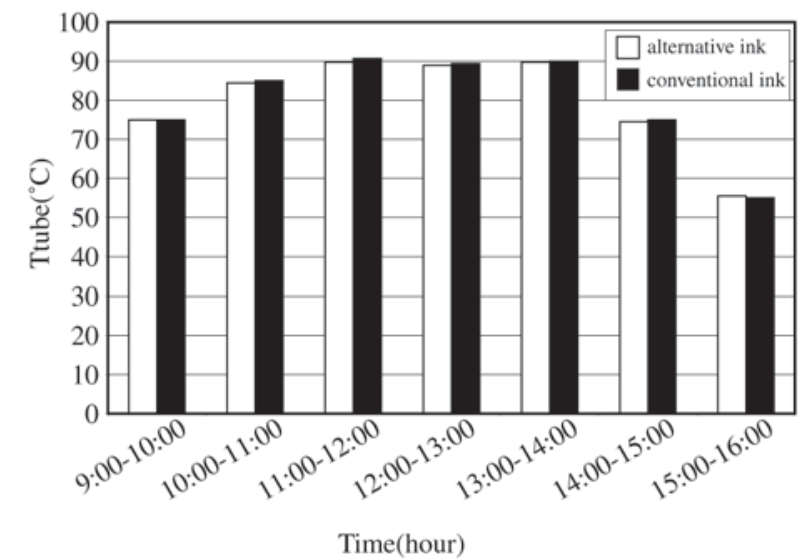

Figure 5. External temperature of the painted tubes with different inks.

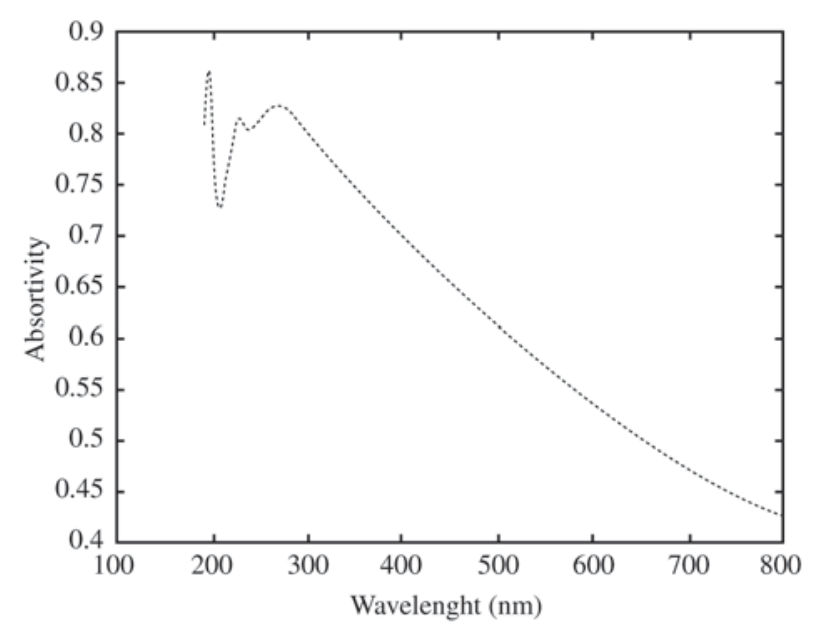

Figure 6. Results of the Analyses Spectrophotometric of the used pigment.

\section{Conclusions}

1. The process of degradation of the tubes of PVC when submitted to the heat and exposed to the solar radiation it is clearly observed, being verified a process of fragility of this material when submitted to these effects;

2. In the case of the use of PVC tubes as elements to absorption has a predominance of the thermal degradation in relation to the degradation for UV, once the ink film protects the tubes of the harmful effects of this radiation type. That thermal degradation more accentuated it is associated to the appearance of double bonds when of the process of unfastening of $\mathrm{HCl}$ of the main chain;

3.The impact test is the one better it translate the level of fragility as a functios of the time of exposure to the sun, demonstrating that such level reaches significant values for the samples with bigger time of exposure in relation to the satandard;

4. Despite of evidence of the fragility level being sufficiently intense, in relation to the impact, such request does not occur in the work condition;

5. The levels of temperature of the tubes of the coil do not reach the critical level in regard to thermal degradation. Therefore it is possible to use a plastic tube, characterized as a thermal insulator, as a conductor of heat, capable to promote the heating water;

6 . The properties of traction, compression and bend resistance to exposed tubes spotted of black ink are increased;

7. The exposed tubes that had bigger time of sun exposure had not presented cracks, holes or another type of attack. Therefore, it shows that the time of useful life of a collector that uses PVC tubes as elements of absorption will be sufficiently long;

8 . The ink produced to serve as alternative in relation to 
the market inks, was shown thermal efficient, also serving as element to soften the degradation for ultraviolet radiation. Your production cost is much smaller than the one of the conventional inks; your absorption power is practically the same and there was not corrosive process in the painted tubes with that ink;

9. The PVC tubes show thermal, material and economic viability of use as elements of absorption in solar collectors. Such collectors can be produced to a lesser cost than the conventional collectors that use tubes of copper, presenting cost of manufacturing of $\mathrm{U} \$ 50 / \mathrm{m}^{2}$, which represents $60 \%$ of the price of the conventional collectors.

\section{References}

1. Property and Specification Charts, By The Editors of Modern Plastics Encyclopedia, The McGraw-Hill, New York, NY, 1996.

2. Mano, E.B. Polímeros como Materiais de Engenharia, Editora Edgard Blucher, São Paulo, 2000.

3. Patel, P.G; Patel, G.R.; Parmar, T.S. Epoxy based thermal stabilizer for polyvinyl chloride, Polymer \& Polymer Composites, v. 9, n. 4, p. 283-290, 2001.

4. Mohamed, N.A.; Sabaa, M.W.; Khalil, K.D. Organic thermal stabilizers for rigid polyvinyl chloride, Polymer Degradation and Stability, v. 72, n. 1, p. 53-61, 2001.

5. Ragab, A.R.; Alawi, H. Weathering effects on the fracture properties of polyvinyl chlorine pipes, Journal of Testing and Evaluation, v. 29, n. 1, p. 44-49, 2001.

6. Gesenhues, U. Influence of titanium dioxide pigments on the photodegradation of polyvinyl chloride, Polymer Degradation and Stability, v. 68, n. 2, p. 185-196, 2000.

7. Rivera, D.A.L. Projeto, Construção e Análise de Desempenho de um Coletor Solar Alternativo a Baixo Custo, Dissertação de Mestrado do Programa de PósGraduação em Engenharia Mecânica da UFRN, 1994.

8. Souza, L.G.M. Sistema Alternativo de Aquecimento Solar, CONEM - Natal, 2000.

9. Souza, L.G.M.; Gomes, U.U. Sistema Alternativo para Aquecimento de Água utilizando Energia Solar, CONEM - João Pessoa, 2002.

10. Souza, L.G.M.; Gomes, U.U. Coletor Solar em Labirinto com Tubos Absorvedores de PVC, CONEM - João Pessoa, 2002.

11. Souza, L.G.M.; Gomes, U.U. Coletor Solar Multitubos de PVC Aletado com um Novo Modelo de Configuração em Série, CONEM - João Pessoa, 2002.

12. Jordan, K.J., Suib, S.L.; Koberstein, J.T. Determination of the degradation mechanism from the kinetic parameters of dehydrochlorinated polyvinyl chloride decomposition, Journal of Physical Chemistry B, v. 105, n. 16, p. 3174 - 3181, 2001.

13. Petre, A. L.; Budrugeac, P.; Segal, E. Thermal Degrada- tion of Polyvinyl Chloride, Journal of Thermal and Calorimetry, v. 56, p.1065-1070, 1999.

14. Fisch, M.H.; Bacaloglu, R. Mechanism of polyvinyl chloride stabilization, Plastics Rubber and Composites, v. 28, n. 3, p. 119-124, 1999.

15. Bacaloglu, R. Degradation and stabilization of polyvinyl chloride. Reaction-mechanism of polyvinyl chloride degradation, Polymer Degradation and Stability, v. 47, n. 1, p.33-57, 1995.

16. Yarahmadi, N.; Jakubowicz, I.; Gevert T. Effects of repeated extrusion on the properties and durability of rigid PVC scrap, Polymer Degradation and Stability, v. 73, n. 1, p. 93-99, 2001.

17. Stipanelov, N.; Klari, I.; Roje, U. Effect of Ca/Zn stabilizer on thermal degradation of polyvinyl chloride/chlorinated polyethylene blends, Polymer Degradation and Stability, v. 74, n. 2, p. 203-212, 2001.

18. Cailean, A. et al. PVC-alkaline earth metal carbonates mixtures. I.PVC thermodegradation in presence of alkaline earth metal carbonates, Materiale Plastice, v. 38, n. 1, p. 45-51, 2001.

19. Torikai A.; Hasegawa, H. Accelerated photodegradation of polyvinyl chloride, Polymer Degradation and Stability, v. 63, n. 3, p. 441-445, 1999.

20. Sullivan, F.R.; Elleithy, R.H.; Abu-Ali, A. Effect of thermal degradation on the impact properties of PVC compounds, Journal of Vinyl \& Additive Technology, v. 5, n. 4, p. 200-204, 1999.

21 Dierickx, W. Changes in Specific Properties of PVC drains under various storage conditions, Agricultural Water Management, v. 37, n. 2, p. 109-119, 1998.

22. Hitt, D.J., Gilbert, M. Tensile Properties of PVC at Elevated Temperatures, Materials Science and Technology, v. 8, n. 8, p. 739-745, 1992.

23. Mano, V.; Felisberti, M.I.; Depaoli, M.A. Influence of $\mathrm{FeCl}_{3}$ on the mechanical, thermal, and dynamic mechanical behavior of PVC, Macromolecules, v. 30, n. 10, p. 3026-3030, 1997.

24. Rao, P.V.C.; Kaushik, V.K.; Bhardwaj, I.S. Microstructural studies on UV-degraded polyvinyl chloride by nuclear-magnetic-ressonance spectroscopy, European Polymer Journal, v. 31, n. 4, p. 341-345, 1995.

25. Zhao, W.W.; Yamamoto, Y.; Tagawa, S. Radiation effects on the thermal degradation of polyvinyl chloride and polyvinyl alcohol, Journal of Polymer Science Part A - Polymer Chemistry, v. 36, n. 17, p. 3089-3095, 1998.

26. Souza, L.G.M.; Gomes, U.U. Viabilidades térmica, econômica e de materiais da utilização de tubos de PVC como elementos absorvedores em coletores de um sistema de aquecimento de água por energia solar, Tese de Doutorado do Programa de Doutorado em Ciência e Engenharia de Materiais da Universidade Federal do Rio Grande do Norte, Natal, 2002. 